\title{
Study on the Impacts of the World's Carbon Emission Trading Market on the Performance of China's Electric Power Enterprises
}

\author{
Jian Chen, Weilun Deng \\ International Business Faculty, Beijing Normal University, Zhuhai, China
}

\section{Email address:}

chenjian@bnuz.edu.cn (Jian Chen)

\section{To cite this article:}

Jian Chen, Weilun Deng. Study on the Impacts of the World's Carbon Emission Trading Market on the Performance of China's Electric Power Enterprises. International Journal of Environmental Protection and Policy. Vol. 7, No. 6, 2019, pp. 161-167.

doi: $10.11648 /$ j.ijepp.20190706.14

Received: August 20, 2019; Accepted: December 9, 2019; Published: December 23, 2019

\begin{abstract}
In recent decade, in order to cope with global climate change, carbon emissions trading markets have emerged around the world. As one of the important industries of the carbon trading market, power companies contributes a lot to the carbon emission mechanism. This paper systematically elaborates the current status of carbon emission trading markets at home and abroad. Taking electric power companies as an example, the authors of this paper analyze the performance system structure of power companies under the context of carbon emissions trading. Through data analysis, under the low-carbon green development policy in China, the carbon emissions trading market is important to the performance development of power companies. This article proposes in the end that the power companies should strive to strengthen internal cost management, actively introduce asset business management systems, and improve asset operation capabilities. At the same time, they should strengthen the development of low-carbon technologies, promote clean energy, and focus on sustainable development, in order to better adapt to carbon emissions trading markets and improve its corporate performance.
\end{abstract}

Keywords: China, Carbon Trading Market, Electric Power Enterprises, Performance, Suggestions

\section{Introduction}

With the rapid development of science and technology and the continuous improvement of the social and economic level, the environmental and resource problems we face are becoming increasingly prominent. Among them, global warming caused by a large amount of greenhouse gas emissions has become an important issue affecting today's global development and cannot be ignored. Since 2006, China has surpassed the United States as one of the world's largest carbon dioxide emitters and one of the developing countries with significant emission reduction potential. At the same time, the Chinese government promises that by 2020, China's carbon intensity will be $40 \%-45 \%$ lower than in 2005. This means that China is an important supplier of global carbon emissions trading and is favored by major developed countries. Power companies, as the industry with the highest carbon emissions, will face enormous opportunities and challenges.

\section{Literature Review}

In terms of the performance of foreign power companies, some scholars such as Subo Kun Muhaka [1] and Mickey Sophie [2] use the marketization degree of the power industry as an important indicator of performance appraisal [3]. In addition, Gemma Luding used the DEA method [4] as a performance evaluation method to compare the production efficiency of Malaysian power companies with other countries [5]. Feiye Steiner [6] proposed that the performance evaluation of power companies can be divided according to whether the links in the industrial chain of power companies are monopolistic [7].

Regarding the research on the carbon emission market transaction model of China's power companies, Ye Zhifang (2019) used DCC-GARCH model to analyze the dynamic relationship between carbon market and energy market in Beijing, Guangdong, Shenzhen, Shanghai and Hubei [8]. 
Ganzi (2018) classifies and analyzes carbon assets, uses real option method to evaluate the value of project-based carbon assets, and selects B-S model to estimate the value of carbon assets [9]. Wu Lichao (2018) introduced an empirical study on the price fluctuations of carbon credits between the EU and China, and analyzed the fluctuations of carbon allowances through a time series model, in order to find the fluctuation law of quota prices in two carbon emission markets [10]. Cui Huanying (2018) used the Nash equilibrium model to obtain the optimal carbon dioxide emissions and total economic growth that maximize the economic and environmental utility of each province, and provide a solution for the initial allocation of carbon allowances [11]. Sun Yue (2018) is based on the formation mechanism of derivatives price in the EU carbon emission trading system. The pricing of carbon futures products should be fully simulated using various pricing models, scientifically quantify futures prices and estimate futures returns [12]. In terms of investigation and research, Wei Wenhui (2017) used the analytic hierarchy process for the analysis of carbon emission reduction costs of power companies, using expert questionnaires to assign weights, and testing as consistent as possible by yaahp software [13]. Yuan Zigan (2017) used the synthetic control method based on counterfactual natural experiments to identify policy effects to examine the impact of carbon emission trading policies [14].

\section{Overview of the World and China's Carbon Emissions Trading Market}

\subsection{Carbon Emissions Trading Market}

Carbon emissions trading is an important mechanism for using the market economy to promote environmental protection. It allows companies to use or trade internal and external energy sources that reduce carbon emissions without breaking the total emissions of carbon emissions trading. According to the 17th theme of the Kyoto Protocol, carbon emissions trading is a tradable quota system based on quotas calculated from commitments and emission reduction commitments listed in Annex B of the agreement. For example, on a global scale, there are only a limited 100 units of carbon emissions, one country receives 20 units of indicators, the country has received 10 units of indicators, and the other countries receive the remaining 70 units. For example, if Country A only launches 15 units and the country has sent 15 units, then State B can purchase carbon emissions from the country's 5 units. At present, the EU is at the forefront of the world in promoting carbon emissions trading. In order to reduce greenhouse gas emissions, the EU has specifically developed a plan for gas emissions trading, which limits carbon emissions to specific sectors.

\subsection{Development Status of Carbon Trading Market}

\subsubsection{Status of Foreign Carbon Trading Market}

As the global carbon trading market continues to expand, the first carbon trading market has become an emerging market. The carbon trading volume of the global carbon trading market was 6.198 billion tons in 2015 , equivalent to 82.873 billion US dollars. Global carbon market trading volume peaked in 2011 and then continued to decline. In 2014, global carbon trading volume decreased by $17.8 \%$ compared with 2013. However, the volume of carbon trading subsequently increased, growing by $27.8 \%$ annually. Firstly, because the EU ETS delayed the carbon emission auction, which led to the rise in carbon prices. Another major reason was the announcement of the Market Stabilization Reserve. The release of foreign exchange reserves enhanced market confidence.

In the world's major carbon trading markets, the EU ETS is at the top of the list. In 2015, the CERs issued by the EU ETS market were \$23 million, 17\% higher than in 2014, and the corresponding circulation. The quantity is 122 million tons of carbon dioxide equivalent. Among them, the trading volume of the primary market is 50 million CERs, which is $17 \%$ lower than that of 2014. The average price in the secondary market is $\$ 0.40$ per ton of carbon dioxide. In the joint compliance mechanism market, the number of emission reduction units issued in 2015 was 200,000 tons of carbon dioxide equivalent, a decrease of $1 \%$ from 14 years, but on January 23, 2015, the price fell to 0.01 US dollars [15].

\subsubsection{Status of China's Carbon Trading Market}

In the practice of low-carbon economic development model, in recent years, China has not only vigorously promoted the development of low-carbon economic industrial systems, such as thermal power generation and emission reduction, new energy vehicles, building energy conservation, industrial energy conservation, but also low-carbon economy industry. The development of the system, such as recycling economy, resource recycling, and environmental protection. Protective equipment and energy-saving materials, as well as carbon emissions trading as a market regulation mechanism, have been a focus in recent years: in 2010, China officially proposed to build a carbon emissions trading system; in November 2011, seven pilot provinces and cities were identified; 2013 In June, Shenzhen launched China's first carbon emissions trading platform. In December 2017, the official release of the National Carbon Emissions Trading Market Construction Plan (Power Generation Industry) marked the establishment of a national unified carbon emissions trading market.

After five years of trials and one year of formal transactions, according to the Prospective Industry Research Institute, as of the end of 2018, China's total carbon emissions trading volume was close to 800 million tons, the largest of which was the Hubei Carbon Emissions Exchange, which reached 330 million tons. 42.14\%; followed by the Shanghai Carbon Emissions Exchange, with a turnover of 190 million tons, accounting for 24.51\%; Fujian Carbon Emission Exchange and Tianjin Carbon Exchange, accounting for $24.51 \%$. Emissions exchange and Chongqing carbon emissions exchanges are still relatively small, accounting for $5 \%$ of the total. 


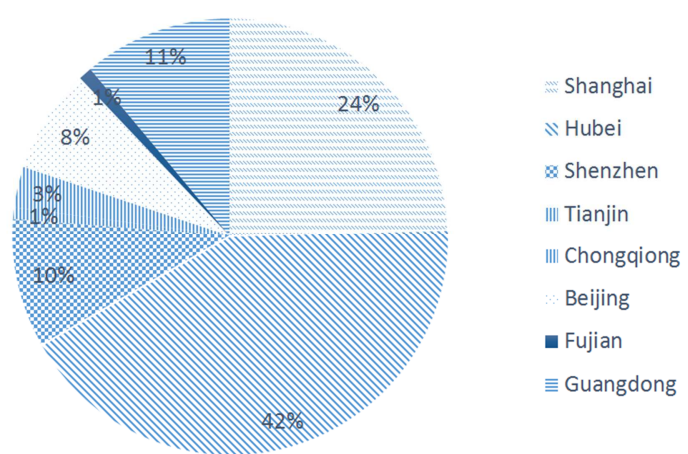

Figure 1. 2013-2018 regional distribution of national carbon emissions trading [16].

Figure 1 shows that at the end of 2018, China's carbon emissions trading volume has exceeded 11 billion yuan, of which Hubei Province carbon emissions trading accounted for $66.51 \%$, Shenzhen carbon emissions trading accounted for 13.34\%, Fujian Carbon Emission Exchange, Tianjin The Municipal Carbon Emissions Exchange accounted for 13.34\%. Compared with the Chongqing Carbon Emission Exchange, the current trading volume is relatively small. They were $1.31 \%, 0.66 \%$, and $2.32 \%$, respectively [16].

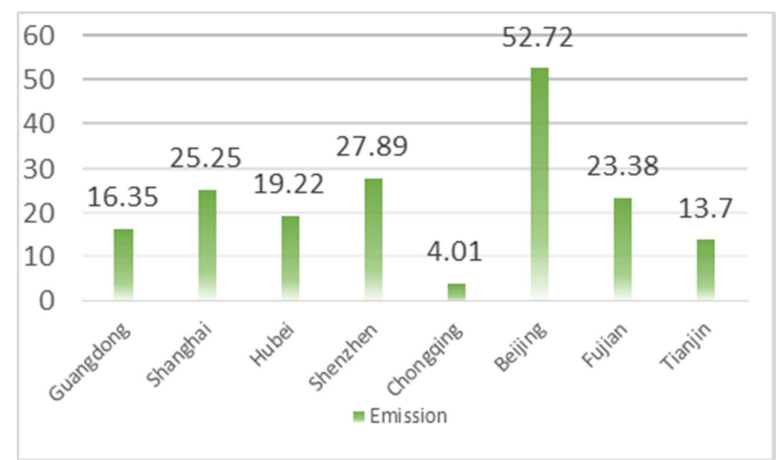

Figure 2. 2018 regional comparison of china's carbon emissions brading prices [17]

As shown in Figure 2, in 2018, the national carbon emissions trading price was headed by Beijing, and Chongqing was at the bottom. Compared with other provinces and cities, Beijing has the highest carbon trading price, which involves Beijing's relevant environmental policies and emission restrictions, which affects the regional carbon price [17].

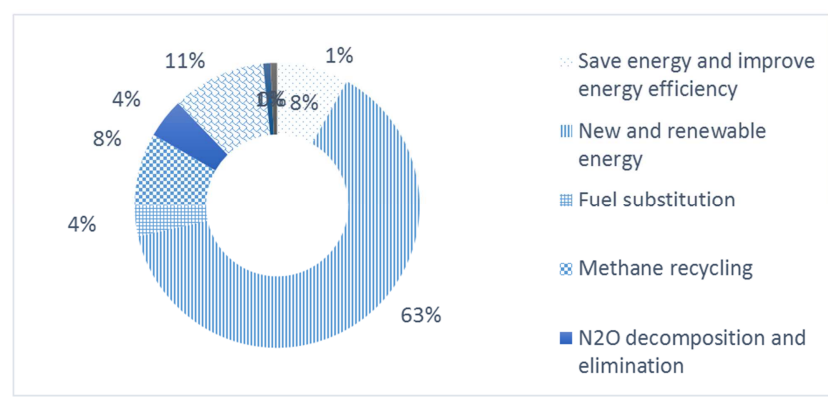

Figure 3. Annual emission reduction of executive board (EB) registered projects by types [18]
According to Figure 3, preliminary estimates by the National Development and Reform Commission, in the long run, the carbon price of 300 yuan / ton is the price standard to ensure the role of low carbon and environmental protection. At present, the average transaction price of many major carbon exchanges in China is only 22 yuan / ton. As it is calculated by the National Development and Reform Commission, the development space of China's carbon trading market is still more than 10 times. [18]

\section{Performance of China's Power Enterprises}

\subsection{Development Status of Power Enterprises Under the Background of Carbon Emission Reduction}

As the basic industry and strategic industry of China's national economy, the power industry is not only an energy production industry, but also a main industry of energy consumption. In recent years, China's power industry has continued to explore and innovate, maintaining a healthy and rapid development [15]. As of the end of 2014, the installed capacity of China's power companies was 1.36 billion $\mathrm{kWh}$, and the annual power generation was 5.55 trillion $\mathrm{kWh}$, reaching the world's first level [19]. In terms of energy conservation and emission reduction, from 2006 to 2014, China's power industry's carbon dioxide emissions have decreased by 6 billion tons. In terms of energy conservation and emission reduction, from 2006 to 2014, China's power industry has reduced carbon dioxide emissions by 6 billion tons [20]. During the "Thirteenth Five-Year Plan" period, the government put forward new requirements for energy conservation and emission reduction in the power industry. For power companies, energy conservation and emission reduction are becoming more and more important. In the future, China will fully realize that it is of great significance to accelerate the energy conservation and emission reduction of power companies for the construction of low-carbon green society, improve the laws and regulations of the power industry, establish and improve a new mechanism for energy conservation and emission reduction in the power industry, and further develop the construction of ecological enterprises. The ecological civilization in China has played a key role in maintaining the sustainable development of the economy and society [21].

The production structure of China's coal-fired power plants is also facing increasing development pressure. Since the "Eleventh Five-Year Plan", large-scale energy-saving and emission reduction technologies have been implemented, and existing coal-fired power plants have relatively low energy conservation and consumption reduction, and the space for improving efficiency is relatively small. At the same time, the proportion of renewable energy sources such as wind power and hydropower is rapidly increasing. Therefore, power companies should accelerate the transformation of development mode, vigorously promote the optimization of energy structure and the upgrading of power production 
industry, adhere to the principle of saving priority, and actively and orderly develop new energy. Prioritize the development of hydropower, safely and efficiently develop nuclear power, natural gas power generation, and a wider range of resources to optimize the distribution of power companies.

During the "Thirteenth Five-Year Plan" period, China's economic development will shift from high-speed to medium-high speed, and the economic structure needs to be adjusted in depth. The new economic normality has led to a slowdown in power consumption growth and continuous optimization of the power production structure. From the industry point of view, in 2015, the total electricity consumption of the whole society increased by only $0.5 \%$, of which the electricity consumption of the secondary industry decreased by $1.4 \%$, and the electricity consumption of the tertiary industry increased by $7.5 \%$. Geographically, electricity consumption in the eastern region increased by only 3.5 percentage points, and the growth rate fell by $3.1 \%$. The electricity consumption in the central region increased by 1.7 percentage points, and the growth rate decreased by 5.2 percentage points, which was the largest drop in growth rate. In the western region, the electricity consumption of the society increased by 6.4 percentage points, and the growth rate decreased by 4.5 percentage points. Electricity consumption in the Northeast region increased by only 1.7 percentage points from the previous year, down $2.6 \%$ year-on-year. It can be seen that electricity consumption in the central and northeastern regions is growing at a slower rate, and the growth rate of electricity consumption in the central and western regions is the region with the largest year-on-year decline.

At present, the concentration of greenhouse gases in the atmosphere is $358.66 \mathrm{ppm}$, and the greenhouse gas (GHG) emitted by coal-fired power generation enterprises is currently 10.3Gt CO2e (including EU 1.6Gt CO2e, North America 3Gt $\mathrm{CO} 2 \mathrm{e}$, China $1.7 \mathrm{Gt} \mathrm{CO} 2 \mathrm{e}$ ), accounting for human greenhouse gas emissions. $24 \%$. The power sector has a large amount of emissions, and the flexibility of the power supply structure changes more than the energy structure of the transportation sector, and the space for emission reduction is large [22].

According to relevant information, nearly $80 \%$ of China's carbon dioxide emissions come from coal burning, while more than $50 \%$ of coal is used for thermal power generation. Therefore, it is of great practical significance to do a good job in calculating greenhouse gas emissions and analyzing the emission reduction potential of power companies to achieve low-carbon economic development and cope with climate change.

\subsection{Research Significance of Power Enterprise Performance System}

\subsubsection{Theoretical Significance}

All along, scholars at home and abroad have paid much attention to the enterprise performance evaluation system. From the perspective of eco-environmental protection issues such as low-carbon economy, it is a change that conforms to the times. In the current society, the reform of the power industry system has entered a new stage. The optimization of resource allocation, efficiency improvement, and cost reduction are all inseparable from corporate performance. In today's society that vigorously develops a low-carbon economy, building a performance evaluation system for power companies based on low-carbon management of power companies is not only important for realizing the strategic goals of power companies, but also beneficial to the long-term theory of power enterprise performance research. development of.

\subsubsection{Realistic Context}

First, according to the relevant environmental protection policies promulgated by the state, power companies will be required to include low-carbon performance assessments in the overall performance appraisal, which will help enterprises to timely identify relevant operational issues and reduce the risks faced by enterprises; Secondly, with the continuous improvement of the system, on the one hand, it is conducive to the internal assessment of power companies, on the other hand, it can bring additional benefits to external investors, which is very conducive to the formation of a good social image. Finally, construct a strategic performance evaluation index system for listed power companies and low-carbon factor indicators to guide the company's low-carbon factors to the strategic goals of each link, and improve the company's environmental awareness. From a realistic macro perspective, if enterprises can actually operate, fully implement the indicator system, achieve energy conservation and emission reduction, and green development, this will greatly help China's ecological environment to protect and improve, and at the same time improve China's international competitiveness.

\subsection{Status of Power Enterprise Performance}

After four years of lows from 2008 to 2011, the power industry has undergone a major shift since 2012. The fall in coal prices has increased the profitability of power companies. In 2013, business performance continued to improve in 2014 and 2015. This year's economic and technical indicators have grown steadily. 2015 is the year of the 12th Five-Year Plan. Affected by macroeconomic policies, the total amount of electricity used by China's society was 5.55 trillion $\mathrm{kWh}$, a year-on-year increase of $0.5 \%$, and the growth rate dropped by $3.3 \%$ year-on-year. With the adjustment of the development structure of China's economy, the power development structure has also undergone a transition from a new normal development stage of heavy chemical industry development. Electric power enterprises should take the initiative to adapt to the requirements of national economic transformation, rapidly adjust and upgrade and upgrade the industrial structure, from large-scale development to quality and efficiency development; from diversification, emphasize the modest extension development mode of the main industry and other industries. At the same time, while maintaining thermal power and increasing the income status, hydropower, wind power, nuclear power and new energy in the environmental protection industry should be given greater advantages to jointly promote the profit level of power companies. 


\subsection{Research of Power Enterprise Performance Evaluation System}

At present, China's power enterprise performance evaluation system is still in the stage of continuous reform and development. The modern enterprise of Chinese power companies is generally different in meaning. Market monopoly in the power industry and lack of motivation to pursue profits. At the same time, the long-term control of the Chinese government and related institutions has made China's power companies lack the ability to cope with market competition. In the current situation, China's power companies still face many difficulties in the process of establishing a performance appraisal system.

\section{Factors Affecting the Performance of China's Power Companies in Carbon Trading Market}

The factors affecting the performance of China's power companies in the carbon trading market can be divided into financial aspects and non-financial aspects.

\subsection{Financial Aspects}

\subsubsection{Profitability of the Company}

For companies engaged in business activities, the direct purpose is to maximize profits and maintain the company's sustainable management and development. From the perspective of the Chinese power company, combined with the environmental background of the power company and the characteristics of the natural monopoly, only by ensuring the profitability of the enterprise itself can the company's technological innovation progress be ensured. So for corporate performance, profitability has a very large impact on it. At the same time, in the early stage of adopting low-carbon technology, the impact of technology on enterprises has a certain lag, and the profitability has not been significantly improved. But after a period of time, after the maturity of technology, it will accelerate the enhancement of corporate profitability.

\subsubsection{Enterprise's Asset Operation Capability}

Asset operation ability is an important factor affecting the performance of an enterprise. It not only reflects the asset utilization rate of the enterprise, but also reflects the business status and management level of the enterprise. Due to the natural monopoly nature of power companies, and the proportion of fixed assets to total assets is over $80 \%$, power companies have several unique characteristics: wide distribution, large number, large scale, and variety. Therefore, for power companies, the development of low-carbon economy has higher technical requirements. For the maintenance and management department of the power enterprise, the department includes various professional technical management departments, such as substation operation, overhaul, transmission, dispatch and communication. As long as the assets and equipment meet the production and operation needs of the enterprise, and a large number of equipment is idle and waste resources, the performance of the enterprise will naturally be improved.

\subsection{Non-financial Aspects}

\subsubsection{Government Factors}

Another important factor affecting performance is the guidance of the government's technological innovation. Companies only realize that if they want to take advantage of the competition, the government has already introduced relevant policies and social environment will play a decisive role. Government funds and technical support are very beneficial to the business development of the company. Throughout the domestic and international carbon emissions market, it can be clearly found that the government's initiatives guide the development of various industries. For example, recent national and local governments have implemented relevant financial subsidies for power companies, tax cuts, land concessions and other implementation policy subsidies, especially in the area of new energy, which has promoted the performance improvement of power companies.

\subsubsection{Technical Factors}

With the reform of China's power system, thermal power plants will become independent power producers with independent accounting and independent financing capabilities. The cost of fuel itself generally accounts for $40 \%$ to $70 \%$. The focus of competition in the electricity market is electricity prices, most of which come from coal. However, the fuel cost is affected by the market price. It is impossible for enterprises to obtain low-cost coal alone to gain an advantage in competition, and the performance of enterprises is difficult to improve. With the development of China's carbon trade, the development of low-carbon technologies can bring opportunities for the company's own efficiency and long-term development. Therefore, only by mastering low-carbon technology for core production can power companies reduce costs and improve their performance.

\section{Recommendations}

\subsection{Internal Corporate}

\subsubsection{Strengthening Internal Management of the Enterprise}

With the introduction of preferential policies by the state and the government, power companies should closely integrate the low-carbon economy with their own development, transform their internal business philosophy, focus on low-carbon environmental protection, and recognize the importance of low-carbon concepts for their long-term development. In addition, through in-depth investigation of the company, in combination with the specific situation of the enterprise, all employees within the enterprise reach a consensus, realize the application of low-carbon technology to the company's production and management, innovate the 
internal management of the enterprise, and implement the low-carbon development strategy of the enterprise.. Therefore from top to bottom, the company has established a sound management system and decomposed the strategic business objectives of the enterprise, which will help achieve the goal. At the same time, combined with the characteristics of the company, establish a responsibility center, allocate low-carbon economic indicators, and establish corresponding reward and punishment mechanisms.

\subsubsection{Enhance the Profitability of Enterprises and Strengthen Cost Management}

According to relevant data, thermal coal accounts for $70 \%$ of the operating costs of power companies. Therefore, better control costs are especially important for power companies. As of December 21, 2012, prices of 5,500, 6,000 and 5,000 calories fell $23 \%, 24.3 \%$ and $23.6 \%$, respectively [15]. And because of this change, after 2012, the profit level of most power companies has greatly improved. However, in order to improve the competitiveness of power companies in the industry, it is necessary to adopt a cost management method in daily production science, and combine advanced energy-saving power generation facilities to improve coal utilization efficiency and control costs within a reasonable range, thereby improving enterprises. Economic benefits. Improve corporate profitability [20].

\subsubsection{Introduce Management System to Improve Asset Operation Capability}

In view of the characteristics of power enterprise assets and possible problems in asset operation, enterprises need to introduce corresponding management systems to improve asset operation capabilities. First, the integration of financial accounting and asset-related business processing is realized by adopting an ERP financial accounting system that is highly integrated with enterprise management. Second, improve corporate asset management practices and develop corresponding indicators to ensure the company's asset operation capabilities. Finally, use core low-carbon technology to maximize the company's asset equipment utilization and improve asset operational efficiency. The above measures

\subsubsection{Focus on Sustainable Development}

Corporate sustainability is the essential feature of a company's long-term development. Only by achieving sustainable development can innovative companies win in the competition. This is especially true for power companies. Traditional power generation accounts for a high proportion of domestic power companies. Considering the current development trend of low-carbon economy, enterprises need to strengthen competition to introduce new energy technologies, focus on the application of low-carbon technologies, and implement intensive operations. By changing the widely dispersed management model in the past, by integrating various resources, enterprises can successfully complete the transformation of a low-carbon economy. At the same time, in the strategic development of the enterprise, vertical focus on specialization, focus on intensification, and enhance the low-carbon development capability of power companies. We will continue to encourage innovation in corporate thinking, technology, talent and management, and ultimately achieve sustainable development of power companies.

\subsection{Outside the Company}

\subsubsection{Strengthen the Guidance of Power Companies}

The power company is a relatively special industry, generally including traditional power generation and emerging environmentally friendly power generation. However, most of China's electricity production still relies on traditional coal-fired power generation. In the process, a large amount of exhaust gas will inevitably be generated, which will seriously affect the power company's energy conservation and emission reduction work. According to the experience of Western countries, relevant departments of the Chinese government should actively guide and promote the development of low-carbon economy and the environmental problems brought by the regulated power industry. With the acceleration of the reform process in the energy sector, the government should speed up macroeconomic regulation and control and coordinate the development of coal and electricity, and plan in detail the support mechanisms for coal and electricity production and transportation, and new energy. Power generation, smart grid, etc., further promote the stable and orderly development of the power market. In order to solve the problem that the overall social responsibility awareness of power companies is not strong, the government may consider introducing relevant technical support and financial support policies to encourage power companies to save energy and reduce emissions. For example, under the conditions of bidding for power plants, the environmental assessment indicators will be increased. Under the same conditions, enterprises with carbon emission standards will have priority in generating electricity on the Internet.

\subsubsection{Develop Low-carbon Technologies and Promote Clean Energy}

As the country promotes a low-carbon economy and a newly established carbon exchange, the requirements of low-carbon technologies for power companies are self-evident. For power companies, the development of the national economy, the demand for electricity will inevitably increase. Therefore, on the basis of development, power companies need to form the fundamental driving force within the enterprise, that is, to vigorously develop low-carbon technologies, reduce carbon emissions, and rationally utilize the opportunities brought about by carbon trading. By increasing investment and continuously improving low-carbon technologies, companies can achieve sustainable development capabilities. Through the continuous application of low-carbon technology, companies can win a competitive position. In addition, power companies should pay more attention to the use of clean energy, and have green passes as the core competitiveness of sustainable development of enterprises. 


\section{Conclusion}

All in all, in the current era, sustainable development, low-carbon economy, circular economy and other concepts are in line with the trend of the times. Low-carbon technologies, new energy and other innovative development areas will also lead our society. As a major energy consumer and pollutant emitter, power companies have an unshirkable responsibility and obligation to reduce carbon emissions and promote the development of China's carbon emissions market. Only in accordance with the situation, the development of energy consumption and pollutant discharge standards, the energy conservation and emission reduction work as an important task of the enterprise, to develop energy-saving emission reduction targets suitable for the enterprise itself, in order to improve economic efficiency and enterprise competitiveness, and promote Sustainable development of the power industry.

\section{References}

[1] Yuan Haixia, Wan Hui, Wang Xiaole, Li Yuchao. Preliminary discussion on the evaluation index system of scientific research performance [J]. Journal of Navy Medicine, 2007 (02): 157-159.

[2] Cai Wenzhao. A New Method of Enterprise Performance Evaluation-Balanced Scorecard [J]. Introduction and Consultation, 2003 (12): 33-34.

[3] Wang Yudan. Research on the evaluation system of power supply enterprise performance under the low carbon perspective [D]. North China Electric Power University (Beijing), 2017.

[4] Wen Subin. Research on the theory and method of enterprise performance evaluation based on sustainable development [D]. Nanjing University of Science and Technology, 2005.

[5] Zhao Xin-gang, Wei Zhen. The technical efficiency of China's wind power list enterprises: An estimation based on DEA method and micro-data [J]. Renewable Energy, 2019, 133.

[6] Song Qiang. Research on Legal Risks and Preventive Measures in the Management of Modern Electric Power Enterprises [A]. Institute of Management Science and Industrial Engineering. Proceedings of 2019 International Conference on Arts, Management, Education and Innovation (ICAMEI 2019) [C]. Institute of Management Science and Industrial Engineering: Computer Science and Electronic Technology International Society, 2019: 5.

[7] Pang Wei. The impact of energy saving and emission reduction on the economic benefits of power companies [D]. Henan University, 2016.
[8] Ye Zhifang. Research on the relationship between China's pilot carbon market and energy market dynamics [D]. Zhejiang University of Finance and Economics, 2019.

[9] Gan Wei. Research on the valuation method of carbon assets based on real option theory [D]. Zhejiang University of Finance and Economics, 2019.

[10] Wu Lichao. Research on EU and China's carbon emissions trading system and market differences [D]. University of Electronic Science and Technology, 2018.

[11] Cui Huanying. Research on carbon emission quota allocation and transaction pricing [D]. Southwest Jiaotong University, 2018.

[12] Sun Yue. Research on EU carbon emission trading system and its price mechanism [D]. Jilin University, 2018.

[13] Wei Wenhui. Accounting and analysis of carbon emission costs in the power industry [D]. China University of Geosciences (Beijing), 2017.

[14] Yuan Zigan. An Empirical Study on the Impact of Carbon Emission Trading Policies on Investment in Power Enterprises [D]. China University of Petroleum (Beijing), 2017.

[15] China's per capita power generation installed capacity broke through 1 kilowatt [J]. Sichuan Hydropower, 2015, 34 (02): 70.

[16] China Economic Net. [EB/OL]. (2018-12-25) [2019-04-01]. Http://www.ce.cn/.

[17] Wang Mingxi, Bao Qin,etc. Enterprises' optimal abatement investment behavior with the carbon emission constraint [J]., Journal of management Sciences in China., 2015, 18 (06): 41-57.

[18] Zhang Qinqin. Research on greenhouse gas emission reduction potential of typical industries in Anhui Province [D]. Hefei University of Technology, 2014.

[19] Zhang Wei. Research on Strategic Performance Evaluation Index System of Listed Power Enterprises under Low Carbon Perspective [D]. East China Jiaotong University, 2016.

[20] Chen Honghong. Development and Prospects of International Carbon Trading Market under the Background of Low Carbon Economy [D]. Jilin University, 2017.

[21] Wu Meina, Wu Weirong. Analysis of Factors Affecting the Performance of Electric Power Enterprises under the Background of Low Carbon Economy and Countermeasures [J]. Contemporary Economics, 2014 (20): 72-73.

[22] Lu Yang. Method of improving the operational efficiency of power companies [J]. Enterprise Reform and Management, 2015 (11): 81. 